\title{
Global Robotics Competition Meets Inclusive Education: The Exceptional Journey of Five Resilient Students
}

\author{
Simon Parent and Sara latauro
}

\begin{abstract}
The 2018 edition of RoboCup allowed young people from Centre de formation en entreprise et récupération (CFER) de Bellechasse to demonstrate their skills in programming and robotics. In this school, as in many schools, the use of technology is a particularly effective learning tool, especially for students facing challenges. The construction of a robotic device has allowed them to develop several skills, some of which can be reinvested in various contexts, whether at school or in their professional life. This commentary briefly presents the exceptional journey of Bellechasse students who were able to overcome many obstacles and compete with gifted students from around the world.
\end{abstract}

\section{Background}

In June 2018, the city of Montreal hosted a major international event: RoboCup 2018. This competition was an opportunity for thousands of elementary, high school, and university students worldwide to demonstrate their knowledge and skills in robotics. These young people include the student team from Centre de formation en entreprise et récupération (CFER) de Bellechasse, a training centre located in the city of Saint-Raphaël, Quebec. These students, many of whom have neurodevelopmental or learning difficulties, are familiar with concrete learning that can have significant repercussions in their daily and professional lives. CFER de Bellechasse places great importance on creativity and collaboration, and is aware of the major contribution of technology, which allows for many ways of knowing.

After much thought, the Bellechasse team members, counting on the support of teacher Elise Croteau and psychoeducator Annick Pelletier, chose to participate in the OnStage component of the competition. Their task was to build a robotic device and integrate it into a stage performance. After competing at the provincial and national level, Bellechasse students reached the international finals and joined approximately 4,000 participants in the 2018 edition of RoboCup. Throughout the process, this competition has demonstrated how the use of technology, and more specifically programming and robotics, can be a powerful inclusive tool for meeting the specific needs of students in the classroom. 


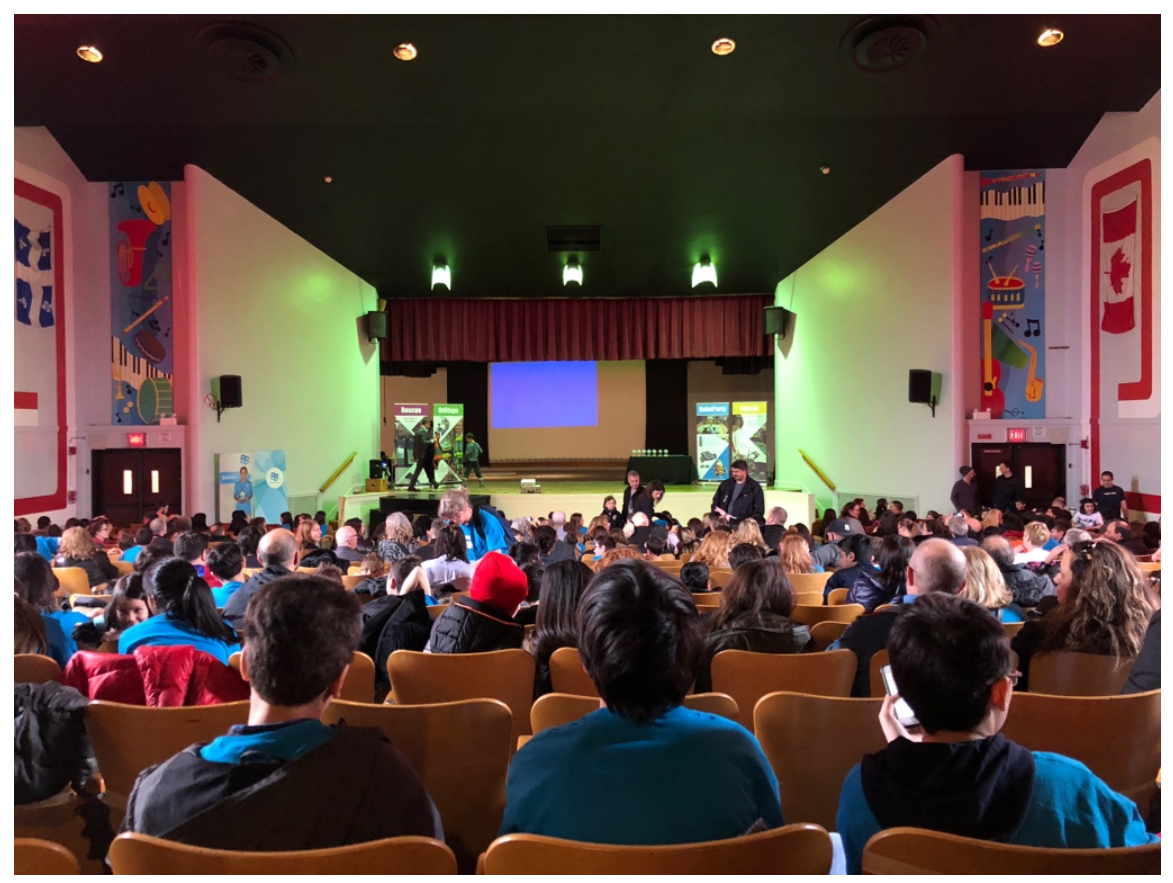

Fig. 1: Provincial qualifications for Quebec (Rosemount Technology Center, EMSB).

These Francophone students (with basic English skills) were able to compete and fully participate in the activities of this major event in which most of the participants were English speakers. They were able to count on the help of two bilingual members of the organizing committee to help them understand all the instructions given to participants. In addition to developing technological skills in programming and robotics, students mobilized their organizational, time management, and stress management skills on numerous occasions, which are critical skills for all students.

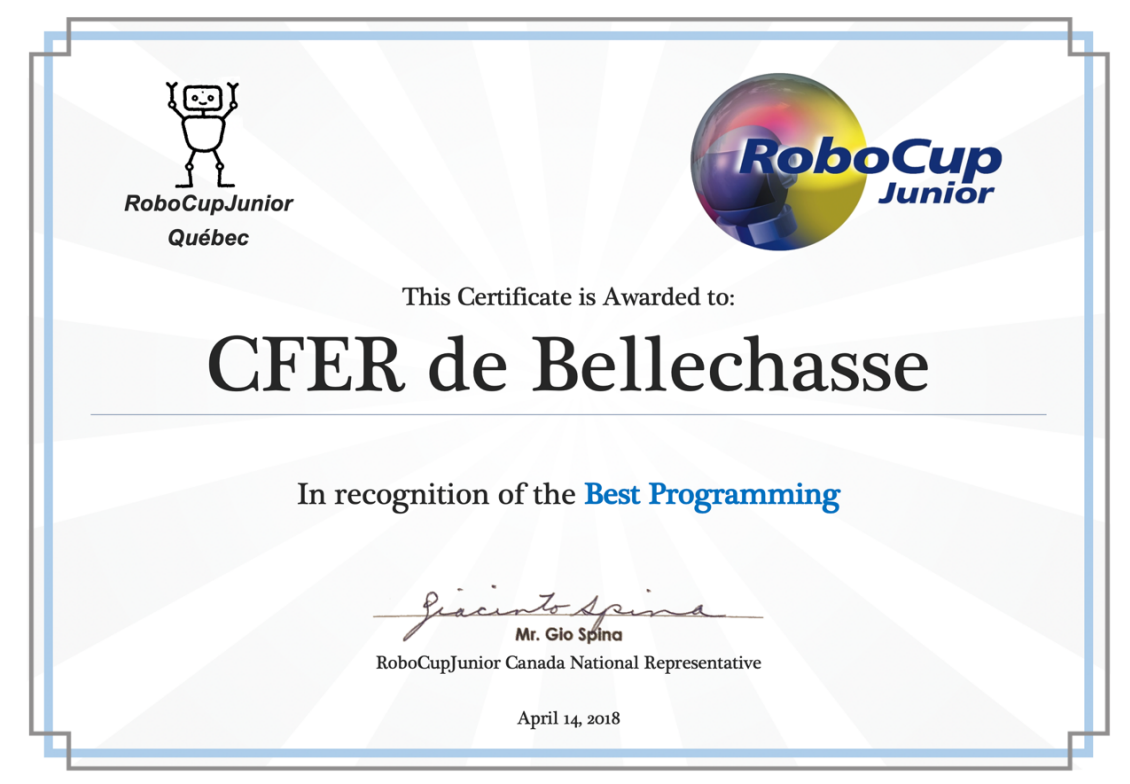

Fig. 2: Certificate awarded to the Bellechasse team at the end of the provincial qualifications. 
As part of the activities of the competition, CFER students had to interact with other students from around the world, which was a particularly valuable opportunity for them to be exposed to other cultures and to develop their collaborative and communication skills. For example, during the SuperTeam Challenge, the CFER team was paired with two other teams from Israel and Portugal to complete a collaborative task. The purpose of this activity was to build a robotic device that could make a work of art, live on stage.

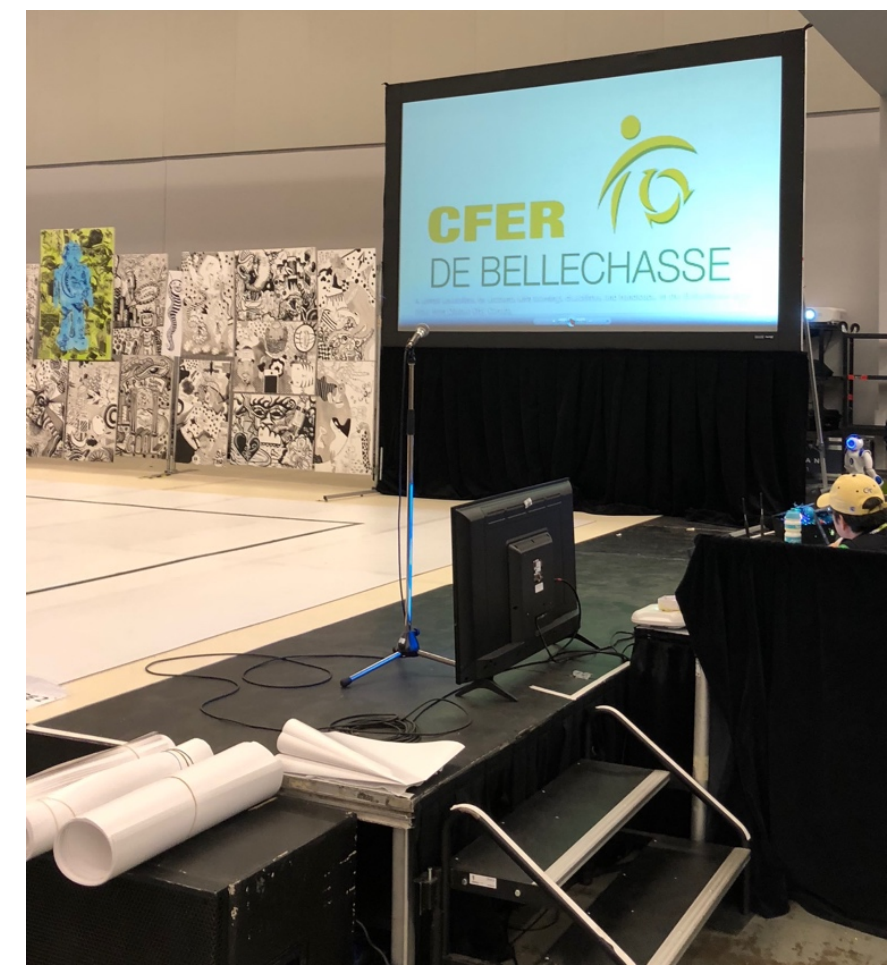

Fig. 3: The students of the Bellechasse team performed on stage with their robots, in front of a hundred spectators.

RoboCup was a highly stimulating learning opportunity for all students, many of whom have different learning profiles and propensities. Robotics is not only for gifted students. The participation of students from the CFER de Bellechasse Centre is an eloquent testimony of engagement and perseverance. We salute the hard work of these young people, which deserves to be highlighted. 


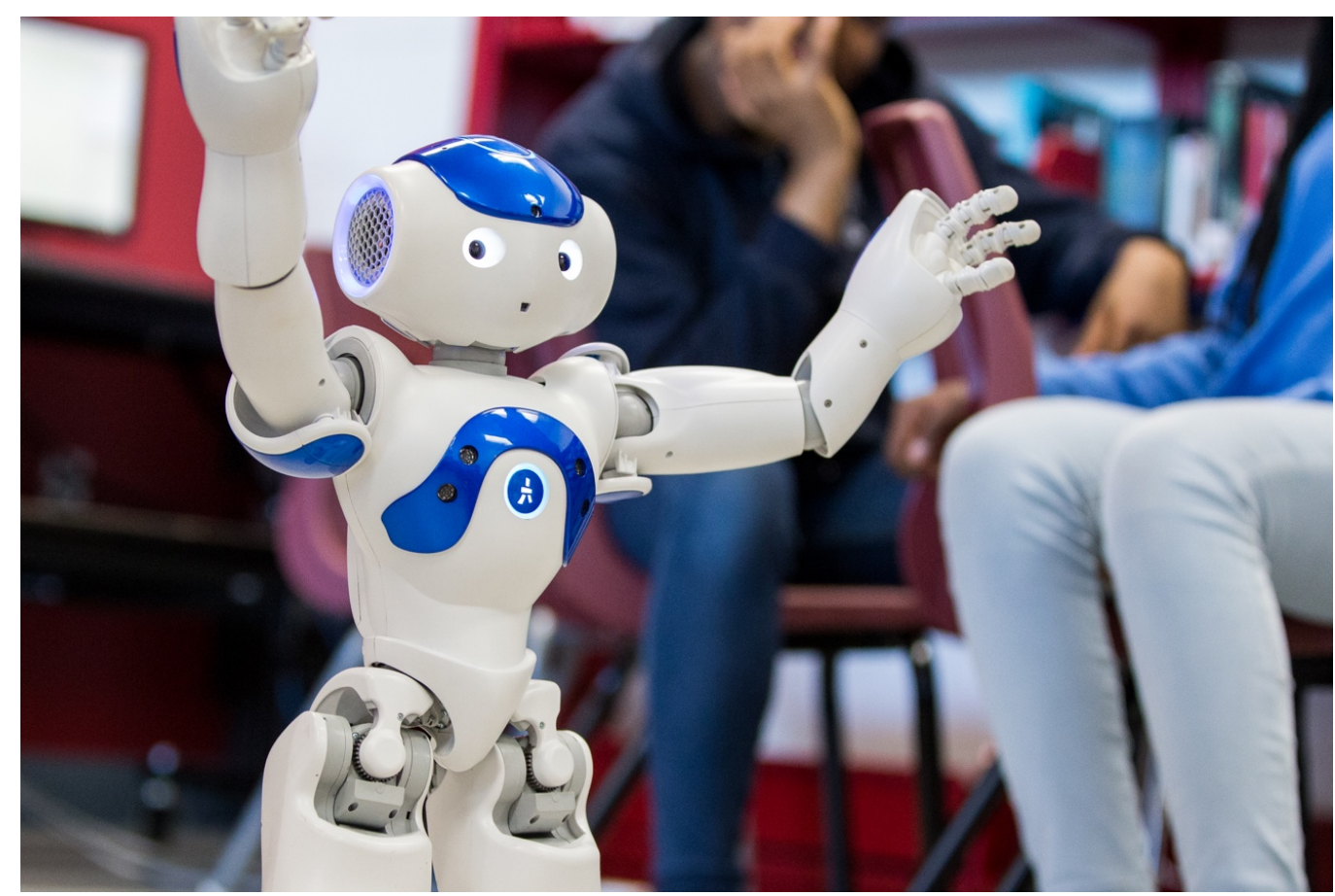

Fig. 4: The NAO robot used by Bellechasse students in their performance.

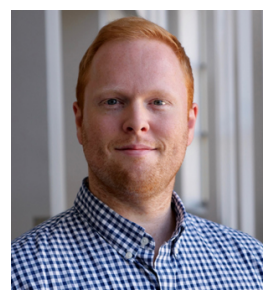

Simon Parent is a PhD student at Université de Montréal, under the direction of Dr Thierry Karsenti. In his research, Simon is interested in the pedagogical use of programming and robotics in elementary school for the development of skills. $\mathrm{He}$ is also the Coordinator of Scientific Research at the Canada Research Chair in ICT in Education, where he has the opportunity to work on different research projects that include e-sports, distance learning for teachers in Niger (UTIFEN project), and the use of video games for learning (Assassin's Creed, Minecraft).

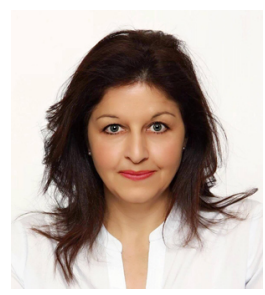

Sara latauro is a Robotics and STEAM Consultant who helps schools integrate Robotics, Science, Technology, Engineering, Arts, and Mathematics creatively in educational curriculums. She specializes in implementing these concepts across disciplines within an inclusive school program for students in Kindergarten to Grade 11. Her graduate research work focuses on technologies and robotics in education to assist teachers in engaging students in a sustainable manner. Since 2006, she has been involved with local and international communities of robotics. RoboCup is the world's largest international competition for intelligent robots and research. Through yearly competitions, the RoboCup community strives to promote the development of robots and artificial intelligence of autonomous machines. 